\title{
AS PRINCIPAIS EVOLUÇÕES DA LEI MARIA DA PENHA EM SEUS 13 ANOS DE VIGÊNCIA
}

\section{THE MAIN EVOLUTIONS OF THE MARIA DA PENHA LAW IN ITS 13 YEARS OF EFFECTIVENESS}

\author{
André Felipe Murta Lemes \\ Bacharel em Direito - Fundação Presidente Antônio Carlos -UNIPAC-Teófilo Otoni/MG, Brasil \\ E-mail: andrefelipemurta@gmail.com
}

Recebido: 01/05/2020 - Aceito: 20/05/2020

\section{Resumo}

O objetivo deste artigo é demonstrar quais foram os principais avanços que a lei Maria da Penha trouxe aos direitos das mulheres, tendo como destaque, a ampliação das diversas medidas protetivas e de urgência em favor da mulher e contra o agressor, assim como medidas assistenciais. Primeiramente, buscou-se analisar o momento da entrada em vigor da Lei Maria da Penha, sendo, por conseguinte, o motivo do aumento das denúncias de violência doméstica e familiar, bem como os benefícios e evoluções que a lei objeto de estudo trouxe para as mulheres. Na conclusiva, foi possível observar, levando em consideração que antes da entrada em vigor da lei 11.340/2006, as mulheres eram tratadas como seres inferiores em relação aos homens, lado outro, que as medidas que protegem as mulheres vítimas da violência doméstica dentro do âmbito familiar, bem como o empoderamento feminino, foram fruto dos avanços que a lei Maria da Penha vem tendo em todo território brasileiro, passando a sociedade enxergá-las com outros olhos.

Palavras-chave: Evolução da lei Maria da penha; Violência doméstica e familiar; Empoderamento da mulher.

\begin{abstract}
The purpose of this article is to demonstrate what were the main advances that the Maria da Penha law brought to women's rights, highlighting the expansion of various protective and urgent measures in favor of women and against the aggressor, as well as assistance measures. Firstly, we sought to analyze the moment of the entry into force of the Maria da Penha Law, and, therefore, the reason for the increase in complaints of domestic and family violence, as well as the benefits and evolutions that the law object of study brought to the women. In conclusion, it was noted that, prior to the entry into force of Law 11,340 / 2006, women were treated as inferior to men, on the other hand, that measures that protect women victims of domestic violence within family, as well as female empowerment, were the result of the
\end{abstract}


advances that the Maria da Penha law has been having throughout the Brazilian territory, allowing society to see them with other eyes.

Keywords: Evolution of the law Maria da penha; Domestic and family violence; Women's Empowerment.

\section{INTRODUÇÃO}

A lei 11.340/2006, denominada como Lei Maria da Penha, desde sua entrada em vigor até os dias atuais, trouxe uma considerada evolução em se tratando de violência doméstica ocorrida no âmbito familiar.

Deve-se considerar, que a referida lei empoderou as mulheres, mudando a visão da sociedade em relação a elas, adotando políticas públicas eficazes para que um dia possa erradicar todo tipo de violência doméstica e familiar em todo território Brasileiro e, retirar o contexto social e cultural de que a mulher é um ser inferior em relação aos homens, sendo este pensamento fruto de uma sociedade ainda patriarcal.

Com a alta da Lei Maria da Penha, aumentaram-se os números das denúncias sobre violência doméstica e familiar nas Delegacias especializadas, bem como nas centrais de atendimento às mulheres, dando o referido aumento em relação ao reconhecimento e visibilidade em que a Lei 11.340/06 tem hoje no país, como menciona "Vera Baroni":

Muitas vezes as mulheres nem sabem dizer as modalidades de violência que sofrem, mas sabem que existe uma coisa chamada Lei Maria da Penha, declara Vera Baroni, integrante da UialaMukaji Sociedade das Mulheres Negras de Pernambuco e da Articulação de Mulheres Negras Brasileiras (AMNB).

Restando assim, que a Lei Maria da Penha está em uma constante evolução diária, começando pelo pretexto do empoderamento das mulheres e, o alto reconhecimento que esta lei tomou no Brasil e no Mundo.

\section{ENTRADA EM VIGOR DA LEI MARIA DA PENHA}

Em agosto de 2006 o então Presidente da República Luiz Inácio Lula da Silva, sancionou a Lei de n⿳亠口冋 11.340, que leva o nome da Farmacêutica Bioquímica Maria da Penha. Esse batismo da Lei com seu nome é uma homenagem a sua luta incessante, usando-a como exemplo do que acontece dentro do âmbito familiar ou de afeto entre o agressor e a vítima, por falta de apoio social e de Leis que protejam as mulheres de agressões e opressões domésticas. 
Desta forma, conforme a contextualidade da lei Maria da Penha, se encontrando em conformidade com a Constituição Federal, a lei 11.340, de 7 de agosto de 2006, prevê tal situação como crime:

Cria mecanismos para coibir violência doméstica e familiar contra a mulher, nos termos do $\S 8^{\circ}$ do art. 226 da Constituição Federal, da Convenção sobre a Eliminação de Todas as Formas de Discriminação contra as Mulheres e da Convenção Interamericana para Prevenir, Punir e Erradicar a Violência contra a Mulher; dispõe sobre a criação dos Juizados de Violência Doméstica e Familiar contra a Mulher; alteração no código de processo Penal, o Código Penal e a Lei de Execução Penal; e dá outras providências (Lei 11.340 /2006).

A Lei Maria da Penha muda o ordenamento jurídico brasileiro e a forma processualística, ao declarar os direitos humanos das mulheres.

No art. $5^{\circ}$ da Lei 11.340/06, esta versa sobre o que é considerado como violência doméstica no âmbito familiar contra mulher, como sendo:

\begin{abstract}
Art. $5^{\circ}$ Para os efeitos desta Lei, configura violência doméstica e familiar contra a mulher qualquer ação ou omissão baseada no gênero que lhe cause morte, lesão, sofrimento físico, sexual ou psicológico e dano moral ou patrimonial: I - no âmbito da unidade doméstica, compreendida como o espaço de convívio permanente de pessoas, com ou sem vínculo familiar, inclusive as esporadicamente agregadas; II no âmbito da família, compreendida como a comunidade formada por indivíduos que são ou se consideram aparentados, unidos por laços naturais, por afinidade ou por vontade expressa; III - em qualquer relação íntima de afeto, na qual o agressor conviva ou tenha convivido com a ofendida, independentemente de coabitação. Parágrafo único. As relações pessoais enunciadas neste artigo independem de orientação sexual (Art. 5', Lei 11.340/06).
\end{abstract}

Dias (2010) orienta que para se identificar bem o que vem a ser considerado como violência doméstica se faz necessário observar o que está declarado no art. $7^{\circ}$ da mesma Lei, por considerar o que declara o art. $5^{\circ}$ pouco detalhado.

O autor acredita que "para se chegar ao conceito de violência doméstica é necessária a conjunção dos art. $5^{\circ}$ e $7^{\circ}$ da Lei Maria da Penha" (DIAS, 2010, p. 51). Com essa orientação fica mais fácil observar que o crime previsto no caput do artigo $5^{\circ}$ da referida lei, se aplica a qualquer relação íntima com envolvimento emocional independente da orientação sexual dos envolvidos.

Saffioti (2001) faz uma definição independente entre a violência doméstica e a familiar.

Segundo o autor, cabem à violência doméstica agressões feitas por pessoas não pertencentes ao grupo familiar, seja consanguíneo ou agregados, o que elenca os casos de abusos às empregadas domésticas, por coabitarem, mesmo que parcialmente, no âmbito domiciliar. Ficam então cabíveis à violência familiar, os casos ocorridos entre indivíduos 
membros da mesma família próxima ou mais distante, mesmo que não estejam dentro das fronteiras do domicílio.

Em observância a lei Maria da Penha, esta trouxe um enorme avanço aos direitos das mulheres, sendo que a partir de sua entrada em vigor, a sociedade passou a olhar com outros olhos as mulheres, começando assim a conquistarem seus espaços.

Podendo ser observado assim, por meio de declaração da jurista de João Pessoa, em entrevista ao Clickpb, um jornal eletrônico da Paraíba-JP. Que para a juíza do Juizado de Violência Doméstica e Familiar contra a Mulher, Rita de Cássia Andrade, depois da lei, as mulheres deixaram o silêncio e partiram em busca de seus direitos, a lei está mudando o quadro de opressão e dando mecanismos às mulheres de proteção e acolhimento. A jurista declara que:

\footnotetext{
Há alguns anos no juizado era observado apenas caso de mulheres de classe média para baixa que denunciavam os agressores. Elas têm mais coragem porque não se preocupam com a repercussão e as aparências na sociedade (,,,) hoje a lei Maria da Penha completa sete anos com uma forte aceitação da sociedade, isso significa que a lei veio para ficar e continua sendo uma das mais importantes do mundo, segundo uma avaliação das Nações Unidas (ANDRADE, 2013, p. web).
}

Com a declaração da jurista da Paraíba é possível perceber que a Lei Maria da Penha contempla todos os eixos no enfrentamento à violência doméstica, seja no combate, na prevenção ou prestação de serviços às mulheres vítimas. Como ressaltou a magistrada, como sendo os objetivos do poder judiciário, através do Tribunal de Justiça e o Juizado de violência doméstica, a garantia dos direitos das mulheres, com o amparo da Lei Maria da Penha.

\section{EMPODERAMENTO DA MULHER}

Deve-se enfatizar que com a alta da Lei Maria da Penha na sociedade, esta trouxe um chamado "Empoderamento Feminino", que veio em razão de que sempre que algum estudo aborda a questão feminina, é apontado ao aspecto de inferioridade ao qual a mulher está submetida. Isso se dá pelo fato de que, por muito tempo, prevaleceu a visão de que homens e mulheres são diferentes entre si por questões biológicas, naturais e a forma que a sociedade se comporta é um reflexo disso. Assim, a mulher ficou em uma condição inferior ao homem, como se este fosse o processo natural de definição de seu lugar no mundo, e essa visão era compartilhada tanto pelos homens como pelas próprias mulheres.

As consequências desta visão engessada sobre o papel do homem e da mulher na sociedade vêm de uma construção histórica, que pode ser chamada de "Gênero", sendo às construções e ás expectativas sociais, políticas e cultural sustentada em relação ao lugar de 
homens e de mulheres, bem como na crítica à existência exclusiva de binarismo para definir a sexualidade das pessoas na sociedade, como exemplo de umas das espécies de gênero, seria a questão biológica, onde para os antigos, não poderia falar de Gays nem em lésbicas, sendo que para estes, o gênero se baseava no aspecto físico do ser humano.

Segundo entendimentos da autora "Simimone de Beauvoir, na obra O Segundo Sexo, escrita em 1949, explana que não se nasce mulher, torna-se mulher”.

Não acredito que existam qualidades, valores, modos de vida especificamente femininos: seria admitir a existência de uma natureza feminina, quer dizer, aderir a um mito inventado pelos homens para prender as mulheres na sua condição de oprimidas. Não se trata para a mulher de se afirmar como mulher, mas de tornaremse seres humanos na sua integridade. (Beauvoir, S.,1949).

Sendo, portanto, com base nessa premissa que se vê a necessidade do empoderamento da mulher, propiciando mudanças no conceito de que as mulheres têm delas mesmas, em razão de uma construção histórica, social e cultural, que foi imposta em uma sociedade patriarcal, melhorando sua autoestima.

O empoderamento vem resgatar a mulher do pior tipo de opressão que existe, aquela que vem de dentro do ser humano, na qual, a própria pessoa se impõe, dada as informações que recebeu ou que passou em seu processo de desenvolvimento.

Em se tratando do empoderamento das mulheres, para que se tenha um bom entendimento sobre o que vem a ser o empoderamento feminino, é bom compreender o conceito de empoderamento e o sentido em que se é empregado. Nothaft (2012) faz uma busca epistemológica da palavra dentro do seu teor científico.

O termo empoderamento, derivado do inglês empowerment, foi utilizado por diversas ciências sociais com intuito de estudar as relações de poder, relacionando-se com os interesses dos despossuídos do poder, no sentido de impulsionar mudanças na cultura e na estrutura da sociedade (NOTHAFT, 2012, p. 24).

Essa articulação de mudanças em prol de melhorias pessoais demonstra uma busca pelo controle nas relações de poder, dentro do convívio social. Esse tipo de controle é à base dos discursos feministas, que encontram no termo um significado próprio de sua luta contra a subordinação da mulher perante uma estrutura social minada pelo machismo, que divide o comportamento humano pelo gênero. (NOTHAFT, 2012, p. 24).

Nesse sentido, com o empoderamento das mulheres que houve com a chegada da Lei Maria da Penha, podemos notar a evolução que está sendo para a sociedade feminina, onde estas estão cada dia ocupando maiores espaços na sociedade, e perdendo o medo de 
denunciarem as violências sofridas no meio familiar. Sendo de se notar, que com o referido empoderamento, aumentaram os números de denúncias nas delegacias especializadas. Razão pela qual, vale destacar que um dos fatores do aumento das denúncias contra violência doméstica e familiar, foram as realizações de Políticas Públicas, como a implantação da central de atendimento à mulher, que facilitou os acessos as informações e denúncias relacionados à violência doméstica no âmbito familiar. 


\section{Tolerância à violência doméstica}

Maioria concorda com prisão para maridos agressores e acha que homem nāo pode gritar com a própria mulher

Homem que bate na esposa
tem que ir para a cadeia (em \%)

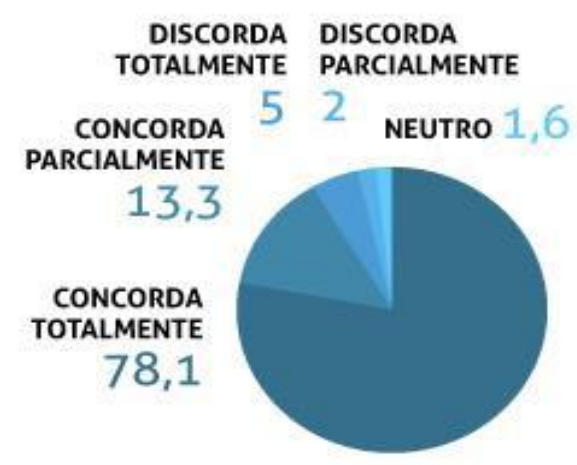

Um homem pode xingar e gritar com sua própria mulher (em \%)

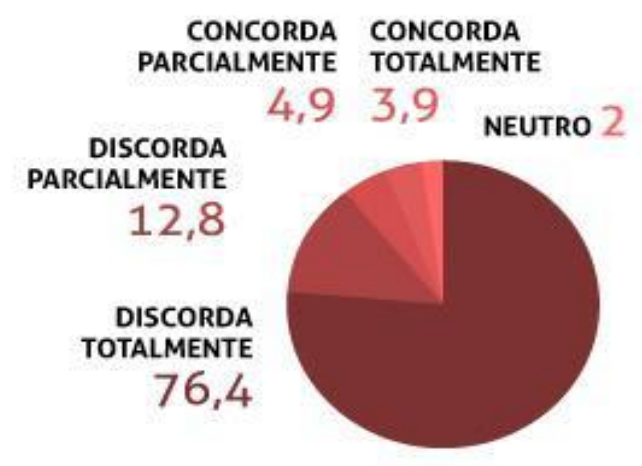

Mulher que apanha em casa deve ficar quieta para não prejudicar filhos (em \%)

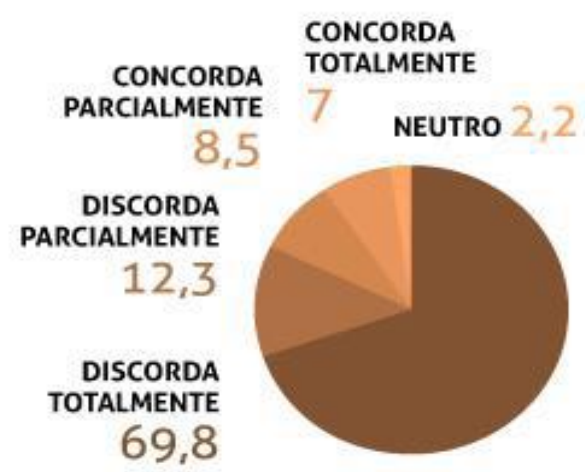

Quando há violência, os casais devem se separar (em \%)

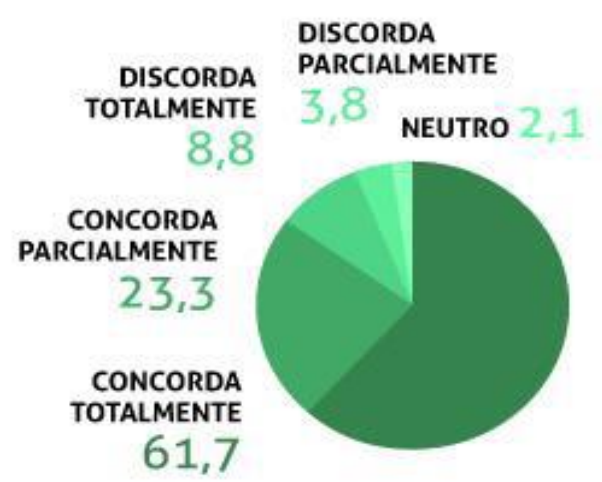

*Pesquisa realizada entre maio e junho de 2013 em todo o Brasil Fonte: Ipea/SIPS Tolerância social à violência contra as mulheres

\section{AUMENTO NAS DENÚCIAS DE VIOLENCIA DOMÉSTICA E FAMILIAR}

Os aumentos referentes às denúncias de violência doméstica no Brasil estão diretamente relacionados ao disque 180 , tendo em vista que o mesmo trouxe uma ampla facilidade em

\footnotetext{
${ }^{1}$ https://dossies.agenciapatriciagalvao.org.br/violencia-em-dados/por-minuto-9-mulhes-foram-vitimas-deagressao-em-2018/
} 
denunciar as violências sofridas, bem como em buscar mais informações relacionadas à Lei Maria da Penha.

A Central de Atendimento à Mulher em Situação de Violência, do Governo Federal, recebeu 38.681 denúncias de janeiro a junho de 2018.

Conforme se demonstra detalhadamente os números registrados pelo Ligue 180:

\section{Comparativo por Tipos de Atendimentos - 10 Semestre (2017 e 2018)}

\begin{tabular}{|l|c|c|c|}
\hline \multicolumn{1}{|c|}{ Tipo de Atendimento } & $\mathbf{2 0 1 7}$ & $\mathbf{2 0 1 8}$ & \% de Aumento \\
\hline Informações & 510.276 & 447.719 & $-12,26 \%$ \\
\hline Denúncias & 38.205 & 38.681 & $1,25 \%$ \\
\hline Relatos de Violência (até 12/6/2018) & 41.029 & 34.158 & $-16,75 \%$ \\
\hline Reclamações & 2.388 & 2.414 & $1,09 \%$ \\
\hline Sugestões & 67 & 42 & $-37,31 \%$ \\
\hline Elogios & 252 & 325 & $28,97 \%$ \\
\hline Total: & $\mathbf{5 9 2 . 2 1 7}$ & $\mathbf{5 2 3 . 3 3 9}$ & $\mathbf{- 1 1 , 6 3 \%}$ \\
\hline
\end{tabular}

Registros de Manifestações - Denúncias - 10 Semestre de 2018

\begin{tabular}{|c|c|c|}
\hline Grupo de Violação & 2018 & $\%$ \\
\hline Violência Física & 16.615 & $43,31 \%$ \\
\hline Violência Psicológica & 12.745 & $33,22 \%$ \\
\hline Violência Sexual & 2.445 & $6,37 \%$ \\
\hline Violência Patrimonial & 647 & $1,69 \%$ \\
\hline Violência Moral & 1.271 & $3,31 \%$ \\
\hline Violência Obstétrica & 60 & $0,16 \%$ \\
\hline Cárcere Privado & 1.430 & $3,73 \%$ \\
\hline Feminicídio & 14 & $0,04 \%$ \\
\hline Tentativa de Feminicídio & 3.018 & $7,87 \%$ \\
\hline Homicídio & 17 & $0,04 \%$ \\
\hline Tentativa de Homicídio & 43 & $0,11 \%$ \\
\hline Trabalho Escravo & 11 & $0,03 \%$ \\
\hline Tráfico de Pessoas & 42 & $0,11 \%$ \\
\hline Esporte sem Assédio & 6 & $0,02 \%$ \\
\hline Total: & 38.364 & $100 \%$ \\
\hline
\end{tabular}




\section{Comparativo - Denúncias e Relatos de Violência: Relação do Suspeito com a Vítima}

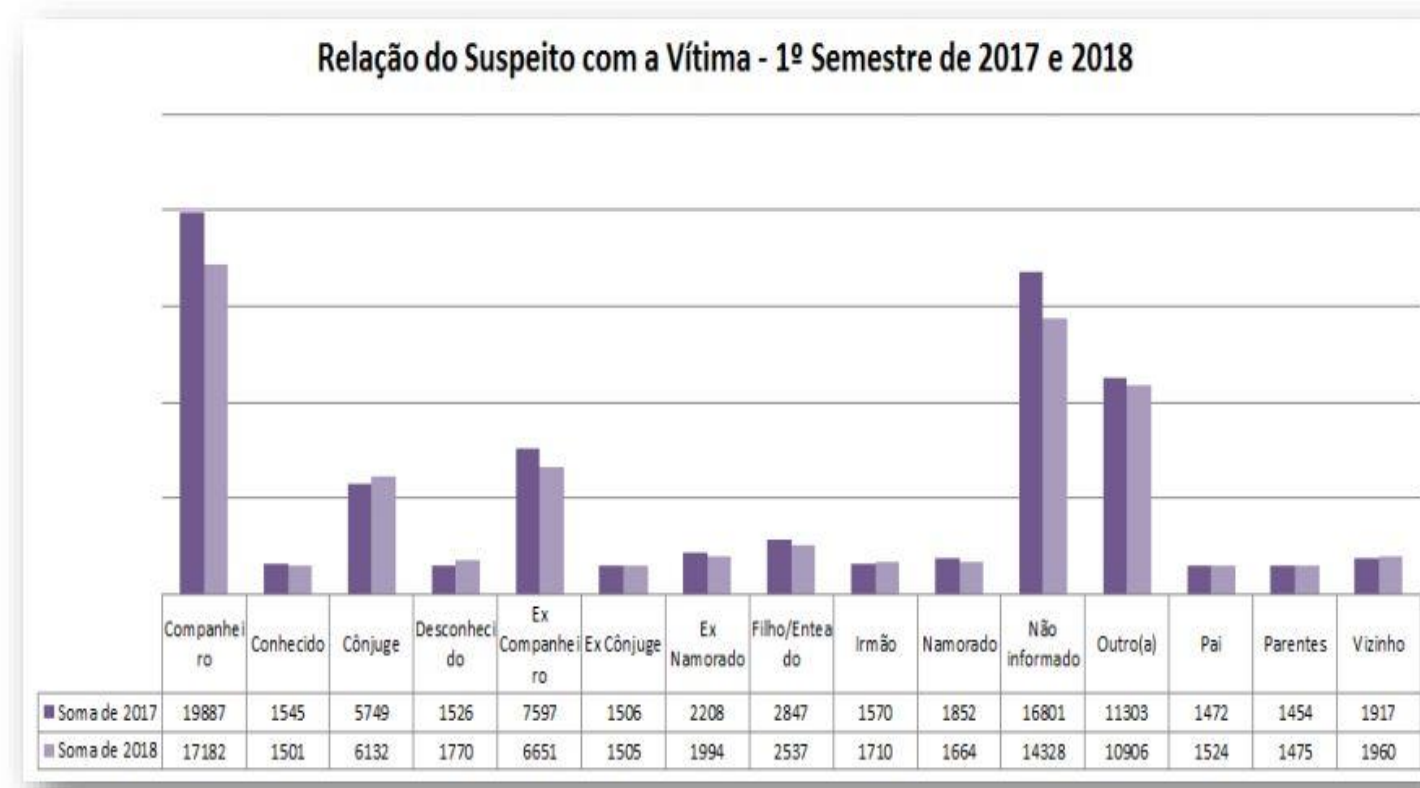

\subsection{SOBRE O LIGUE $180^{3}$}

Nesse sentido, a "Central de Atendimento à Mulher em Situação de Violência" é um serviço gratuito do governo federal que atende ininterruptamente os pedidos de informações sobre direitos das mulheres e registram denúncias de violência, realizando quando necessário o encaminhamento para os vários órgãos da rede de atendimento.

Sendo, portanto, vários os tipos de violência no âmbito do atendimento do Ligue 180, como por exemplo, violência: física, doméstica, sexual, moral, patrimonial, obstétrica, no esporte, contra a mulher imigrante, emigrante e refugiada, cárcere privado e crimes cibernéticos.

Segundo dados do instituto Patrícia Galvão, são 606 casos por dia de lesão corporal dolosa em contexto de violência doméstica e familiar no Brasil.

\footnotetext{
${ }^{2}$ https://www.mdh.gov.br/informacao-ao-cidadao/ouvidoria/RelatrioSemestral2018.pdf ${ }^{3}$ https://dossies.agenciapatriciagalvao.org.br/violencia-em-dados/por-dia-606-casos-de-lesao-corporaldolosa-enquadrados-na-lei-maria-da-penha/
} 


\subsection{DADOS DA CENTRAL DE ATENDIMENTO À MULHER ${ }^{4}$}

Conforme dados do serviço de telefonia ligue 180, o mesmo realizou 749.024 atendimentos no ano de 2015. Sendo que deste montante, 41,09\% foram correspondentes à prestação de informações; 9,56\%, a encaminhamentos para serviços especializados de atendimento à mulher; $38,54 \%$, a encaminhamentos para outros serviços de tele atendimento (190/Polícia Militar, 197/Polícia Civil, Disque 100/SDH).

Em comparação a 2014, houve um aumento de: 44,74\% no número de relatos de violência, 325\% de cárcere privado (média de 11,8/dia), 129\% de violência sexual (média de 9,53/dia), $151 \%$ de tráfico de pessoas (média de 29/mês), podendo ser percebido este aumento conforme informações prestadas no site Brasil.gov, que informam que o Ligue 180 realizou mais de um milhão de atendimentos a mulheres em 2016, sendo este número $51 \%$ superior ao registrado no ano de 2015, quando 749.024 mulheres foram atendidas pela centra.

Considerando as evoluções da Lei Maria da Penha em seus 13 anos de vigência, vale destacar que operando no sentido de impedir o crescimento descomunal da violência contra a mulher nos últimos anos, a lei serviu para poupar vidas e para conter inúmeros casos envolvendo agressões de gênero.

Segundo relatório do Instituto de Pesquisa Econômica Aplicada (Ipea), a saber, o número de homicídios de mulheres, caíram 10\% no Brasil desde o surgimento da Lei Maria da Penha. "Uma redução de 10\% nos feminicídios cometidos dentro de casa".

Os resultados da pesquisa indicam que a Lei Maria da Penha (Lei ${ }^{\circ}$ 11.340/2006) trouxe uma diminuição acerca de $10 \%$ sobre os homicídios contra as mulheres praticados em suas próprias residências.

${ }^{4}$ http://www.compromissoeatitude.org.br/alguns-numeros-sobre-a-violencia-contra-as-mulheres-nobrasil/ 


\section{Taxa de homicidios ocorridos em residência - Brasil (2000-2011) \\ (Por 100 mil habitantes)}

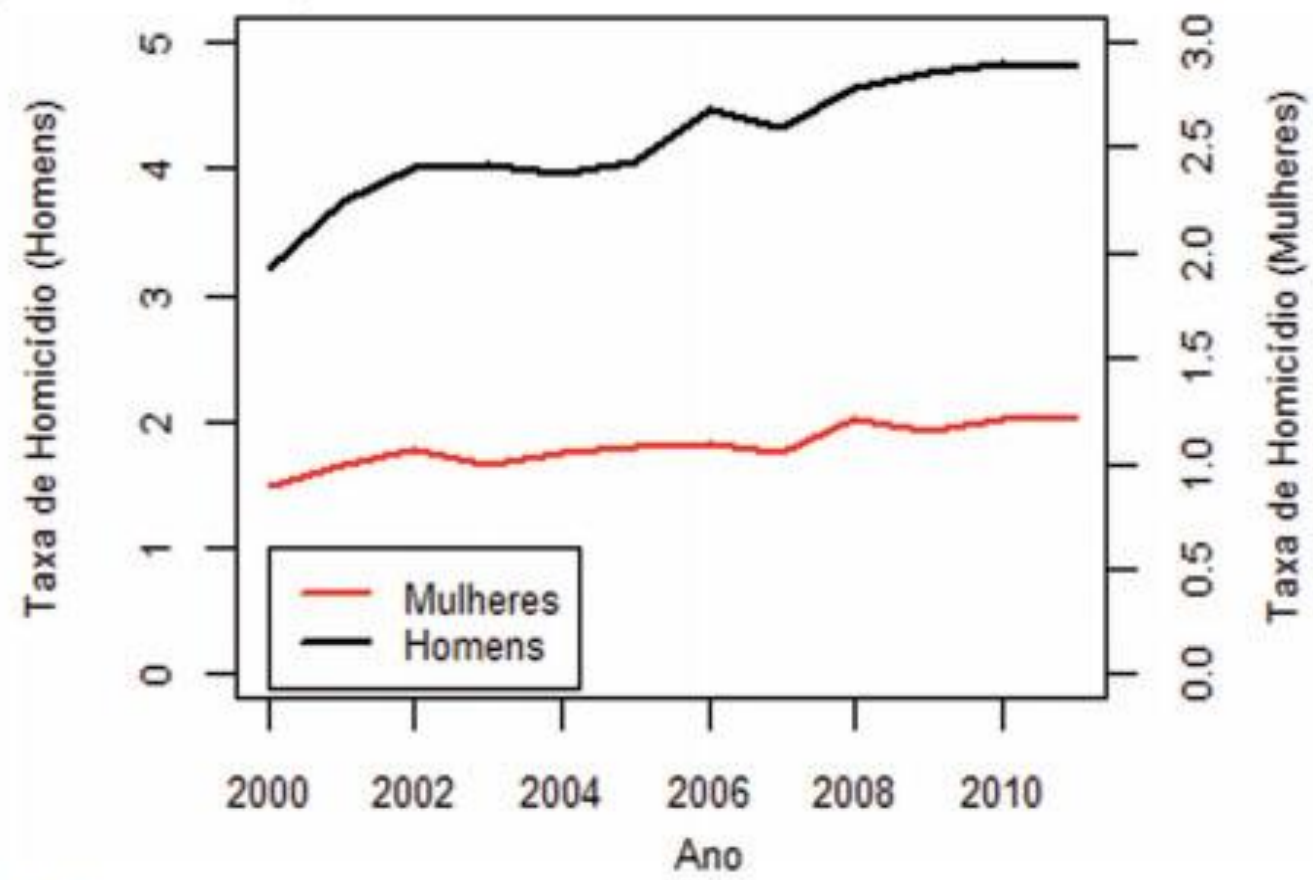

Fonte: SM

Elabaracia: Dies:lesea.

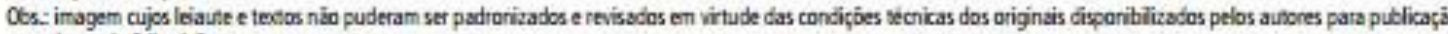
(nota do Editorialn.

\section{MEDIDAS PROTETIVAS DE URGÊNCIA}

A Lei Maria da Penha dedica o capítulo II as medidas protetivas de urgência, porém essas medidas não se limitam somente ao referido capítulo, pois, no próprio corpo da Lei há outros dispositivos de cunho protetivo.

Dias enfatiza que:

A inclusão da vítima em programas assistenciais (art. $9^{\circ}, \S 1^{\circ}$ ) tem nítido viés protetivo. Dispõe da mesma natureza a possibilidade de assegurar a vítima servidora pública acesso prioritário à remoção. Trabalhando ela na iniciativa privada, lhe é garantida a manutenção do vínculo empregatício, por até seis meses, se necessário seu afastamento do local de trabalho (art. $9^{\circ}, \S 2^{\circ}$, II). (DIAS, 2007, p. 79).

Nesse sentido, Cunha e Pinto esclarecem que a intenção perseguida pelo legislador “"[...] é evitar que a ofendida seja tomada de surpresa, sem chance de acautelar, principalmente com 
eventual ordem de soltura do agressor." Logo, "a medida não deixa de ser positiva afinal, quem se sente perseguida deve ter noção de onde anda o agressor". (CUNHA; PINTO, 2007, p. 84), (NUCCI, 2006, p. 878).

Dias afirmou que "o legislador fez a sua parte. Agora é a vez da Justiça”, portanto, inúmeras são as providências que o Poder Público pode tomar ao ter ciência da prática de violência doméstica e familiar perpetrada contra a mulher. (DIAS, 2007, p. 142).

Sendo assim, em treze anos, a lei contou com muitas evoluções e algumas se destacam, incluindo "A ampliação das diversas medidas protetivas e de urgência em favor da mulher e contra o agressor, assim como medidas assistenciais.

Entre elas, está o afastamento do suposto agressor do lar ou local de convivência com a vítima, a fixação de limite mínimo de distância, a restrição do porte de armas e o encaminhamento da mulher e de seus dependentes a programas oficiais ou comunitários de proteção e atendimento.

Devendo destacar ainda, como uma das medidas mais atuais hoje na lei Maria da Penha, é a inclusão do artigo 12-C, incluído pela Lei 13.827/2019, onde o referido artigo, flexibiliza as formas de adoção das medidas protetivas de urgência.

Sendo, portanto, em razão do mencionado artigo, autorizando que a própria autoridade policial (delegado de polícia) possa adotar as referidas medidas em seu próprio município, salvo se este for sede de comarca, bem como o referido artigo também autoriza a adoção das medidas pelos policiais civis e militares.

Levando em consideração que as medidas só serão adotadas por policiais civis ou militares, se no Município não tiver delegado disponível no momento da denúncia e nem for sede de comarca, devendo ambos comunicar o juiz no prazo máximo de 24 horas, e o juiz decidirá, em igual prazo, sobre a manutenção ou a revogação da medida aplicada, devendo dar ciência ao Ministério Público concomitantemente.

Art. 12-C. Verificada a existência de risco atual ou iminente à vida ou à integridade física da mulher em situação de violência doméstica e familiar, ou de seus dependentes, o agressor será imediatamente afastado do lar, domicílio ou local de convivência com a ofendida:I - pela autoridade judicial;II - pelo delegado de polícia, quando o Município não for sede de comarca; ou III - pelo policial, quando o Município não for sede de comarca e não houver delegado disponível no momento da denúncia.§ $1^{\circ}$ Nas hipóteses dos incisos II e III do caput deste artigo, o juiz será comunicado no prazo máximo de 24 (vinte e quatro) horas e decidirá, em igual prazo, sobre a manutenção ou a revogação da medida aplicada, devendo dar ciência ao Ministério Público concomitantemente. $§ 2^{\circ}$ Nos casos de risco à integridade física da 
ofendida ou à efetividade da medida protetiva de urgência, não será concedida liberdade provisória ao preso. ${ }^{6}$ (Artigo 12-C, Lei 11.340/2006).

\subsection{DADOS RELACIONADOS ÀS MEDIDAS PROTETIVAS DE URGÊNCIA}

Em 2017 foram concedidas 236.641 medidas protetivas de urgência, um aumento de $21 \%$ em relação a 2016, quando foram expedidas 194.812 medidas. Considerando a quantidade de mulheres residentes por UF, as maiores médias de medidas expedidas a cada mil mulheres foram registradas pelo TJDF $(7,3)$, TJRS $(6,7$ medidas), TJMS $(6,3)$, TJMT $(5,4)$ e TJES (4,3); já as menores médias foram verificadas nos TJs de Alagoas, Acre, Sergipe e Bahia.

Em 2017 ingressaram nos tribunais de justiça estaduais de todo o país 452.988 casos novos de violência doméstica contra a mulher, aumento de $12 \%$ em relação a 2016, com 402.695 casos novos. O TJSP apresentou o maior volume, com 67.541 processos novos; em seguida vêm o TJRS (66.355), o TJMG (47.320) e o TJRJ (46.340). Os menores números de casos novos foram registrados pelo TJAL (1.300), TJRR (1.409) e TJAP (2.936).

Já em relação ao número de casos ainda pendentes em violência doméstica contra a mulher, em 2017 havia 908.560 casos pendentes, um aumento de $2 \%$ sobre 2016, quando se registravam 891.818 casos pendentes.

Foram baixados na Justiça Estadual um total de 540.156 processos de conhecimento criminais em violência doméstica contra a mulher em 2017, número $18 \%$ superior ao baixado em 2016, quando foram decididos 456.858 processos. Os tribunais com as maiores quantidades de processos baixados em 2017 foram o TJRS (111.752), o TJRJ (69.675) e o TJMG (62.321).

Em 2017 os Tribunais de Justiça estaduais registraram 2.643 casos novos de feminicídio. O relatório esclarece que, por se tratar de previsão em lei recente (a Lei n ${ }^{\circ}$ 13.104, ou Lei do Feminicídio, foi promulgada em 2015), alguns tribunais, como o TJAP e o TJAL, não dispõem dessa informação. ${ }^{7}$

\section{CONSIDERAÇÕES FINAIS}

Levando em consideração os dados mais recentes retirados do "Instituto Patrícia Galvão", a Lei Maria da Penha está entre uma das Leis mais importantes do mundo, porém com

${ }^{6}$ http://www.planalto.gov.br/ccivil 03/ ato2019-2022/2019/lei/L13827.htm

${ }^{7}$ https://dossies.agenciapatriciagalvao.org.br/dados-e-fontes/pesquisa/o-poder-judiciario-naaplicacao-da-lei-maria-da-penha-cnj-2018/ 
seus 13 anos de vigência, ainda temos dados bastante entristecedores de violência doméstica e familiar contra a mulher.

Destacando-se que em 2018, 536 mulheres foram vítimas de agressão física a cada hora; 4,6 milhões de mulheres foram agredidas fisicamente por motivos sexuais e, a cada minuto 9 mulheres foram vítimas desse tipo de agressão em 2018; ou que 12,5 milhões, foram vítimas de ofensa verbal, como insulto, humilhação ou xingamento; ou 1,7 milhão, foram ameaçadas com faca ou arma de fogo; e, 1,6 milhão, sofreram espancamento ou tentativa de estrangulamento, tendo em vista que esse número representa 3 por minuto.

Salienta-se ainda que entre 83 países, o Brasil está entre o $7^{\circ}$ mais violento para as mulheres, de acordo com a organização mundial de saúde(OMS).

No entanto, a expectativa é que a sociedade se desenvolva mais e passe a não tolerar de forma alguma qualquer tipo de violência, sendo desde a mais simples a mais grave, considerando que essas violências podem chegar a um contexto irreversível, tendo em vista que a mesma é universal, atinge mulheres e homens de todas as classes da sociedade, de todas as idades, de todos os graus de escolaridades, e de todas as raças. ${ }^{8}$

Embora muitos avanços tenham sido alcançados com a Lei Maria da Penha (Lei $n^{\circ}$ 11.340/2006), ainda assim, tem que ser mudado muitas coisas para que em um futuro próximo, a sociedade veja a Lei Maria da Penha como uma Lei que cumpriu com sua finalidade, erradicando todo tipo de violência doméstica contra a mulher e, mudando o contexto histórico e social da sociedade brasileira.

8Fonte: Visível e Invisível: A vitimização de mulheres no Brasil - 2 a Edição (Datafolha/FBSP, 2019) https://dossies.agenciapatriciagalvao.org.br/violencia-em-dados/por-minuto-9-mulheres-foram-vitimasde-agressao-em-2018/ 


\section{REFERÊNCIAS}

BEAUVOIR, Simone de. O Segundo Sexo, v.I, II. Tradução Sérgio Milliet. Rio de Janeiro: Nova Fronteira, 1980.

CUNHA, Rogério Sanches; PINTO, Ronaldo Batista. Violência doméstica: lei Maria da Penha (lei 11.340/2006) comentado artigo por artigo. São Paulo: Ed. Revista dos Tribunais, 2007.

DIAS, Maria Berenice Dias. A lei Maria da Penha na Justiça: a efetividade da

Lei 11.340/2006 de combate a violência doméstica e familiar contra a mulher. São Paulo: Ed. Revista dos Tribunais, 2007.

NUCCI, Guilherme de Souza. Leis penais e processuais penais comentadas. São Paulo: Revista dos Tribunais, 2006.

NOTHAFT, Raíssa Jeanine. A autonomia da mulher na lei maria da penha: uma análise da Ação Declaratória de Inconstitucionalidade 4424 do Supremo Tribunal Federal.. 2012.

Disponível em: <https://www.lume.ufrgs.br/bitstream/handle/10183/67452/000872125.pdf?se quence $=1>$. Acesso em: 14 abr. 2018.

SAFFIOTI, H. Movimentos sociais: Face Feminina. In: Carvalho, N. V. (Org.). A Condição Feminina. São Paulo: Vértice. 1988. p. 143 - 178.

SAFFIOTI, Heleieth. Gênero, patriarcado, violência. São Paulo: Fundação Perseu Abramo, 2004.

SILVA, Maria de Fátima. O Segundo Sexo. Condição feminina sob o jugo da tradição. In: GIL, Isabel Capeloa; Manuel Cândido PIMENTEL (Org.). Simone de Beauvoir. Olhares sobre a Mulher e o Feminino. Lisboa: Nova Vega, 2010, p.85-98. TARRANT, Shirra. When sex bacame gender. New York: Routledge, 2006.

http://www.brasil.gov.br/cidadania-e-justica/2017/03/ligue-180-realizou-mais-de-um-milhaode-atendimentos-a-mulheres-em-2016.

https://mdemulher-abril-com-br.cdn.ampproject.org/v/s/mdemulher.abril.com.br/estilo-devida/lei-maria-da-penha-afinal-o-que-mudou-nesses-dezanos/amp/?amp_js_v=a2\&amp_gsa=1\&usqp=mq331AQECAFYAQ\%3D\%3D\#referrer=https $\% 3 \mathrm{~A} \% 2 \mathrm{~F} \% 2 \mathrm{Fwww}$. google.com\&amp tf $=$ Fonte $\% 3 \mathrm{~A} \% 20 \% 251 \% 24 \mathrm{~s} \&$ ampshare $=\mathrm{https} \% 3 \mathrm{~A}$ $\% 2 \mathrm{~F} \% 2 \mathrm{Fmdemulher}$ abril.com.br\%2Festilo-de-vida\%2Flei-maria-da-penha-afinal-o-quemudou-nesses-dez-anos $\% 2 \mathrm{~F}$.

https://www.migalhas.com.br/dePeso/16,MI243907,91041-

A+Lei+Maria+da+Penha+e+seus+avancos+no+combate+a+violencia+domestica. http://www.ebc.com.br/instituto-patricia-galvao. Fonte: Visível e Invisível: A vitimização de mulheres no Brasil - $2^{\text {a }}$ Edição (Datafolha/FBSP, 2019). https://dossies.agenciapatriciagalvao.org.br/violencia-em-dados/por-minuto-9-mulheresforam-vitimas-de-agressao-em-2018/. 